\section{PHOTO STORY}

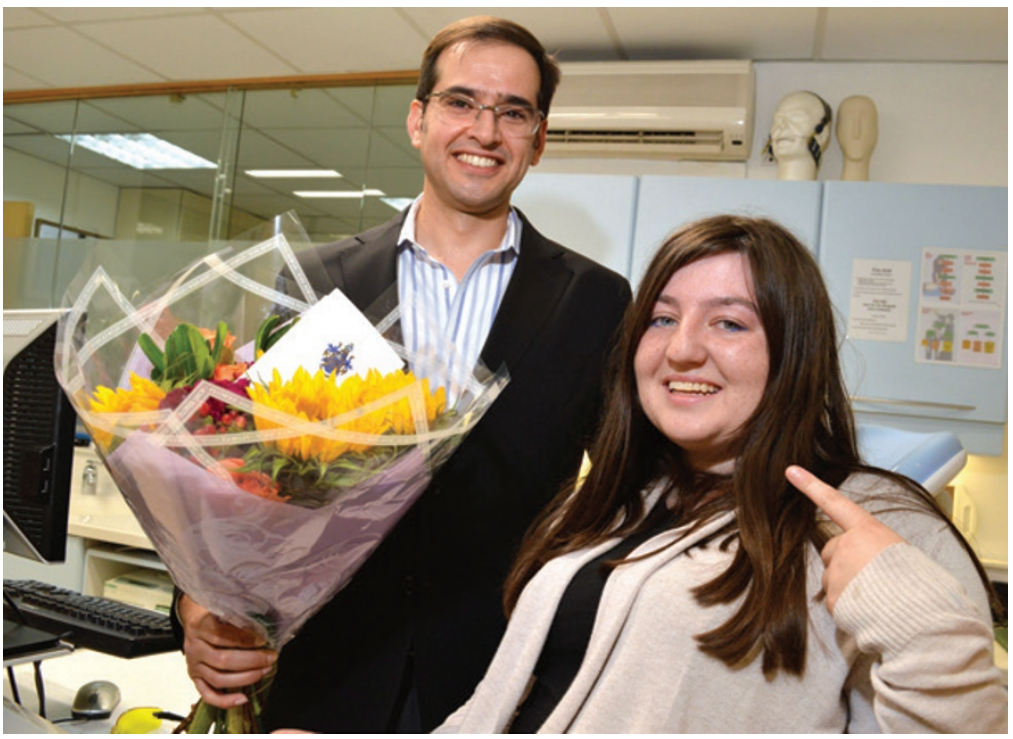

Battersea-based orthodontist Dr Adil Mannan (pictured left) won the British Orthodontic Society's 'Against the Odds' competition, for helping patient Jade McGuigan, 19 (pictured with Dr Mannan), to smile again. Jade, who has learning difficulties, speech problems and suffers from anxiety, needed a brace for years but was too afraid to go to the dentist. When her mother took her to see Dr Mannan, his reassuring manner put her at ease and she was able to complete two years of treatment.

\title{
DEVELOPING GREEN CREDENTIALS
}

\section{Green innovation}

Wise Dental Practice in Devonport, Plymouth, has been recognised as the 'Greenest' Dental Foundation Training practice in the South West Region. Partners Malcolm Prideaux and Bridget Ashton were delighted to be presented with a Gold Standard award and to find that they had also been given the special award for innovation. Their environmentally friendly practices include composting teabags and food waste in a wormery and rolling waste paper into logs to be used as fuel.

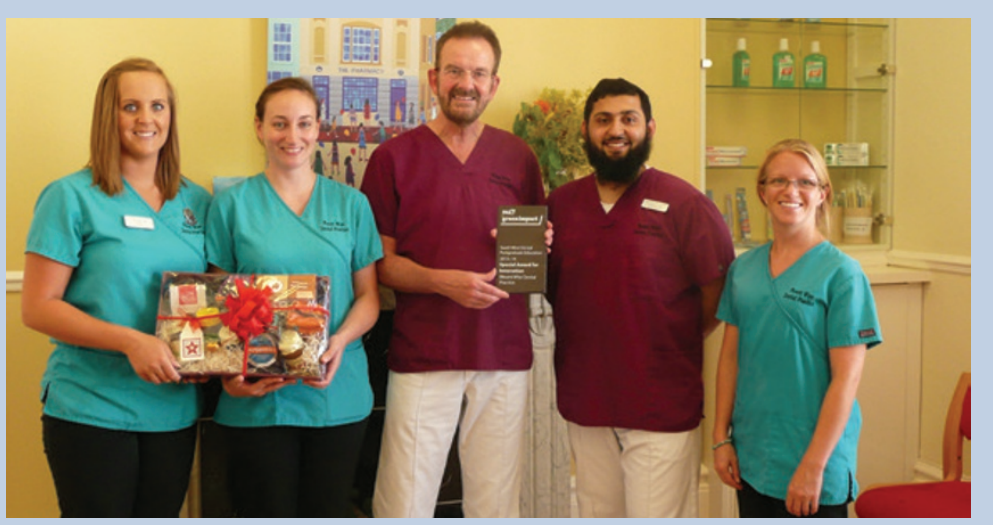

The team at Wise Dental Practice in Devonport with their green award

\section{Green Achiever gold award}

Preston-based Lane Ends Dental Practice has become the first dental practice in the country to attain Green Achiever gold award status, highlighting its commitment to the environment. The practice has made significant progress in reducing its consumption of energy, water and raw materials through, for example, the segregation of both clinical and non-clinical waste, with further separation of recyclable waste, energy-efficient LED and reflective fluorescent lighting and the use of digital X-rays, thus eliminating the need for traditional film-based chemicals. www.greenachiever.co.uk

\section{BOOK REVIEW}

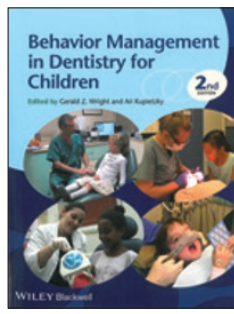

BEHAVIOR MANAGEMENT IN DENTISTRY FOR CHILDREN, 2ND EDITION

\section{G. Z. Wright, A. Kupietzky (eds)}

Wiley Blackwell

price £56.99; pp 264

ISBN 9781118547533

Behaviour management is crucial to successfully providing paediatric dental care and this second edition of Behavior management in dentistry for children certainly provides the reader with the information to do so. The editors Gerald Z. Wright and Ari Kupietzky, coupled with an array of contributors, have developed this book with two main aims. The first is to convey the basic principles of child development and behaviour and the second is to explain the various techniques available to manage this, thus helping to ensure a positive dental experience for the child.

The layout of the book is logical, with the early chapters dealing with child development, behaviour and the influence of family and the dental setting on this. Later, the book explains the different strategies used to manage behaviour beginning with non-pharmacologic techniques and then progressing to chapters covering various methods of sedation and general anaesthesia. Along the way there are excellent sections covering the management of children with various impairments and disabilities as well as behavioural issues, such as attention deficit hyperactivity disorder (ADHD).

The chapter of the book covering local anaesthesia is particularly useful, providing an excellent guide to anyone wishing to administer local anaesthetic successfully to a child. Being very well illustrated, this section clearly demonstrates how to undertake various paediatric local anaesthesia techniques whilst maintaining the patient's cooperation.

Another particularly good feature is that the main text is interspersed with highlighted boxes containing clinical cases. These provide examples of situations when communication or behaviour management has failed and then explain how the situation could have been handled differently. These are particularly useful in demonstrating how the techniques described can be integrated into everyday clinical practice. In addition to this there are continual examples of conversations with children written into the text to demonstrate the use of language and descriptors appropriate to paediatric patients.

Overall Behavior management in dentistry for children provides a comprehensive guide to paediatric behavioural management and will cater for anyone looking to improve their skills in this area, particularly dental undergraduates or those in early clinical training posts.

D. FINN 